\title{
PRO-ENVIRONMENTAL BEHAVIOUR OF ATTENDEES AT A MAJOR SPORT EVENT IN CAMEROON
}

\author{
Frinwei N. ACHU* \\ University of KwaZulu-Natal, School of Social Sciences, Durban, \\ South Africa, e-mail: achufrinwei@gmail.com
}

\begin{abstract}
Citation: Achu, F.N. (2019). PRO-ENVIRONMENTAL BEHAVIOUR OF ATTENDEES AT A MAJOR SPORT EVENT IN CAMEROON. GeoJournal of Tourism and Geosites, 27(4), 13071320. https://doi.org/10.30892/gtg.27416-435
\end{abstract}

\begin{abstract}
This study sought to examine the pro-environmental behaviour of attendees at a major sport tourism event in Cameroon. Through a mixed-methods research technique involving face-to-face surveys with $n=759$, the key findings of the study were that the event attendees displayed inconsistent behaviour while at home, versus while being at the event. The study found that the attendees were more pro-environmentally friendly during the event than they were when they were at home. This was mainly triggered by the emphasis on environmental initiatives and messages conveyed during the event. The study concludes that, since the event attendees are likely to be more pro-environmentally friendly during the event, such events are critical as avenues to creating a lasting impression on the attendees that could address their behaviour during the event, and encourage them to continue thereafter. In this sense, the learning provided through initiatives and branded messages during the event is very important.
\end{abstract}

Key words: Pro-environmental behaviour, attendees, major sport events, Cameroon

\section{INTRODUCTION}

Every human activity has an impact on the environment, as do tourism and sporting events. Environmental consciousness and the complexity of the engagement of various strategies taken both independently and unanimously by the affected stakeholders in the sport events industry has, in the past few decades, been accorded ample scholarship by a number of sports tourism scholars (see Wernerfelt, 1984; Oliver, 1992; Hart, 1995; Hart \& Milstein, 2003; Russo \& Fouts, 2007; McCullough \& Cunningham, 2010). A key issue that continues to echo in the literature of sport tourism is that all of the many typologies of sport events generate environmental issues and subsequently call for the need to evaluate human behaviour regarding the sport event environment (Thibault, 2009; Pfahl, 2011; Trendafilova et al., 2013). Collins et al. (2009), in particular, highlight that the communities, situated in the private and public sectors where the sport events (big and small alike) are staged, have come to recognise the

\footnotetext{
* Corresponding author
} 
significance of the sustainable usage and protection of the environment for sports, and that the environmental consequences of human behaviour, in this regard, command intensified courtesy. The increased amount of attention given to the environmental consequences of sport events is neither new to the present generation, nor confined to any economic system, political climate or social dynamic, but rather, the issues are a result of human nature, thereby requiring global attention (Prizzia, 2007; Suzuki, 2007; Foss, 2009). In the above regard, sport organisations, globally, have come to acknowledge the environmental consequences of fans' and participants' environmental behaviour at major sporting events (Inoue \& Kent, 2012; Pfahl, 2013), and are actively involved in efforts to address such (Collins et al., 2009). The United Nations Environmental Programme [UNEP] (2009) and McCullough et al. (2016, p. 1042) propose the Olympic Games in Beijing, China, as an example of the above, in terms of which the Games organisers "spent over US $\$ 17$ to address environmental issues" of sport events between 2001 and 2007. In another example, according to the Fédération Internationale de Football Association [FIFA] (2013), the Green Goal programme was implemented for the soccer World Cup staged in 2006 in Germany, aimed at reducing the major soccer event's impact on the global climate to the absolute minimum (FIFA, 2013).

Following the successful implementation of the Green Goal programme in 2006, other soccer World Cup bidders, such as South Africa committed themselves to, and adopted, the Green Goal initiative for the hosting of the 2010 event. Such initiatives are particularly useful in managing, or minimising the associated impacts.

Some scholars (see for example Cantelon \& Letters, 2000; Jones, 2008; Collins et al., 2009) have argued that major sport events impact upon the local ecosystems, utilising reserves of irreplaceable natural capital, and contributing to carbon emissions related to climate change and pollution, as well as promoting irresponsible behaviour towards the environment (Han et al., 2015). While the major sport events organisers are increasingly becoming more environmentally sensitive in their planning and hosting of such events, the pro-environmental behaviour of the events' target groups, fans/supporters and participants remain a major concern (Tolkes \& Butzmann, 2018). The current research endeavour was motivated by calls made by some authors (see Mair \& Laing, 2013; Tolkes \& Butzmann, 2018; Macintyre et al., 2019) continuously to examine the environmental consequences of events holistically, with a focus on the different sport events hosted in various geographical contexts. Such an examination, they posit, should deepen the understanding of how the impacts of the events on the economy and society, as well as, most importantly, on the environment, are viewed and attended to. The present research considered the pro-environmental behaviour of the attendees of a major sport event in Cameroon. The study examined the behaviour of the international visitors who attended the twelfth edition of the Africa Women Cup of Nations in 2016. The above was done by considering their environmental behaviour, both at home and during the event.

\section{ENVIRONMENTAL SUSTAINABILITY AND MAJOR SPORT EVENTS}

The sport event industry has achieved substantial growth over the last few decades, with Schimmel (2012) attributing such growth to the much-publicised economic, social and symbolic significance of major sport events (Turco et al., 2012; Tichaawa \& Bob, 2015; Tichaawa et al., 2015). The hosting of major sport events has been intertwined with leveraging the inherent socio-economic, urban regeneration and tourism benefits (Bohlmann \& Van Heerden, 2005; Tichaawa, 2015; Davies, 2016; Xue \& Mason, 2017; Hemmonsbey et al., 2018; Hemmonsbey \& Tichaawa, 2018a,b; Tichaawa et al., 2018; Hemmonsbey \& Tichaawa, 2019). As a result, an increasing number of countries are seeking to host large-scale sport events, with the impacts of major sport events having 
come under scrutiny, specifically regarding the realisation of the promised benefits (see Davies, 2010; Taks, 2013; Adams \& Piekarz, 2015; Taks et al., 2015; Bell \& Daniels, 2018). Increasingly, sport event sustainability has gained much prominence in the scholarly literature (Sotiriandou \& Hill, 2015). Sustainability in events, in the context of the present study, refers to the triple-bottom-line, in terms of which the related economic, social and environmental concerns are posited as being of equal importance and thereby as deserving of equal consideration in the planning and management of sport events (Fyall \& Jago, 2009). The growing interest in sport event sustainability arises from the industry trends, including the globalisation of sport, which attracts substantial numbers of attendees to hosting destinations, the increase in the strategic leveraging of major and mega sport events, the global movement towards sustainability and subsequently the inclusion of sustainability principles in the bidding and hosting requirements of mega and major sport events (Dolf \& Teehan, 2014; Pereira et al., 2014; Han et al., 2015; McCullough et al., 2015; Boggia et al., 2018; Casper et al., 2019).

Predominantly, most academic research examines the economic and social sustainability of sport events (see Smith, 2009; Balduck et al., 2011; Li \& Jago, 2013; Taks, 2013; Ramchandani et al., 2014; Djaballah et al., 2015; Han et al., 2015; Schnitzer et al., 2017), so that, only recently has the inquiry into the environmental sustainability of sport events grown. Environmental sustainability can generally be understood in terms of the sport event industry, as consisting of the organisers involved striving to attain minimal impact on the natural environment in the hosting of such an event (Mair \& Laing, 2013). The present study extends the understanding of environmental sustainability by including consideration of the actions and behaviours of sport event attendees. The environmental sustainability of major sport events has become of importance to a number of stakeholders, ranging from sport event organisers and sponsors, to policymakers and sport event attendees (Bama \& Tichaawa, 2015; Han et al., 2015; Boggia et al., 2018; Habitzreuter \& Koenigstorfer, 2018; López-Bonilla et al., 2018; Minoli et al., 2018; Alonso-Vasquez et al., 2019; Casper et al., 2019; Chirieleison et al., 2019). McCullough and Kellison (2016) opine that an inquiry into environmental sustainability emerges from the inevitable impact of sport events on the natural environment, ranging from the construction of sport event facilities and stadia, as well as the subsequent operations, through to the travel-related implications of sport event attendees for the natural environment (Dolf \& Teehan, 2014; Fekry et al., 2014).

McCullough et al. (2015) reason that environmental sustainability is no longer a pressing concern for policymakers, but that it should rather be of urgent interest to the industry as well. Achieving environmental sustainability in sport events has grown to be a widespread objective, in relation to which various approaches have been taken by the different stakeholders concerned in addressing the matter. According to Sotiriadou and Hill (2015), the sport event industry, specifically sport event organisers, have been the first stakeholder group to direct the development of environmentally sustainable sport events. The most prominent examples are those that are concerned with the hosting of mega sport events, owing to their size and international spectacle.

For instance, the International Olympic Committee (IOC) took the lead in addressing environmental concerns, with a noticeable example being the formulation of the Olympic Games Global Impact (OGGI) study in 2003, which in addition to identifying possible legacies and establishing a benchmark for future Olympic Games, conformed to the stipulation for environmental protection (Mallen et al., 2010). An additional noteworthy example emerges from the 2006 FIFA World Cup, held in Germany, which was the first of its kind to address environmental concerns (Sotiriadou \& Hill, 2015). The Organising Committee having learned from the 2000 Sydney Olympic Games included a 
chapter concerning the issue of environmental sustainability, before the undertaking of an environmental assessment became a requirement for FIFA (Sebake \& Gibberd, 2008). The mega sport event concerned established environmental sustainability programmes, including the responsible use of energy resources and water, a waste disposal strategy, and encouraging the use of public transport to reduce the carbon footprint left by the sport event attendees (Mallen et al., 2010). The aforementioned mega sport events set a precedent for the future hosting, and planning, of sport events. The above is supported by the international sport event organisers, like FIFA, the IOC and UEFA, enforcing the significance of environmental sustainability within the bidding process, as well as strongly encouraging the organisation of green events (Collins \& Flynn, 2008; McCollough et al., 2015). Similar trends have been identified in relation to other major sport events.

For example, the Fédération Internationale de Motocyclisme (FIM), in Switzerland, implemented their environmental code in partnership with the UNEP in 2006, with it focusing on minimising pollution (noise and ground), as well as on incorporating contractual requirements for the conducting of environment-friendly procedures by the event caterers (Mallen et al., 2010). Additionally, the World Championships of the International Amateur Athletics Federation (IAAF), held in Helsinki, Finland, ran the 'Ecomass' programme, which focused on managing the carbon footprint of the event, as well as on minimising its environmental effects (Mallen et al., 2010).

Moreover, the sport event organisers, within the different hosting destinations, have established environmentally responsible measures, such as recycling systems and waste management and environmental campaigns in the hope of encouraging proenvironmental behaviour from the sport event attendees (Han et al., 2015). McCullough and Kellison (2016) further mention the fan engagement activities that form part of the corporate social responsibility of the sport event organisers and sponsors in an effort to encourage sustainable attendee behaviour. Fan engagements that are environmentally driven are motivated by a number of reasons, including the need for the increase in fan identification, cost-saving, the promoting of positive environmental behaviours, and the increasing of the positive perceptions of the sport event organisers (Casper et al., 2019). Reaching out to the sport event attendees has, thereby, become a part of the organisations' contribution towards environmental sustainability, with the objective being to instil pro-sustainable behaviour in the attendees (Kellison \& Kim, 2014; McCullough \& Kellison, 2016; Casper et al., 2019). In agreement with the above, McCullough and Kellison (2016) caution that sport event organisers and sport organisations can strategically leverage their brands so as to promote sustainable behaviours by the sport event attendees. A number of challenges exist in terms of promoting pro-environmental behaviours in sport event attendees, with McCullough and Kellison (2016) suggesting that a major challenges in engaging sport event attendees in sustainability initiatives being that the attendees are primarily concerned with consuming the sport event experience, so that the sport event organisations find it challenging to enforce sustainability, as there is a risk of alienating their fans. As such, a few studies have endeavoured to assess the factors influencing the pro-environmental behaviour of sport event attendees.

\section{Pro-environmental behaviours and attitudes}

Sport event organisations are noted as having increased their efforts to encourage pro-environmental behaviour among attendees, including embarking upon green event strategies and campaigns (Casper et al., 2016; McCullough \& Kellison, 2016). Proenvironmental behaviour has been defined as being the conscious behaviour that aims at minimising the adverse impacts of the natural environment (Kollmuss \& Agyenan, 2002). The authors note that understanding what constitutes pro-environmental behaviour among sport event attendees is complex. In an attempt to understand their pro- 
environmental behaviour, Mair and Laing (2013) point to the social psychological theory that explains human behaviour as being determined by the individual, as well as by external environmental factors. Similarly, Miao and Wei (2013) posit that, due to the influence of contextual circumstances, people tend to display certain behaviours, depending on the specific setting concerned. Numerous departure points have evidently been set for understanding the phenomenon, with some studies having found that social norms and social identity tend to influence the environmental behaviour of attendees.

For example, Han et al. (2015) found that the attendees' belief in what constitutes acceptable behaviour forms a powerful agent in relation to individual behaviour. Additionally, studies have alluded to the inconsistency found in environmental behaviours at the different sport event destinations, and in the daily life of the sport event attendees (Mair \& Laing, 2013; Miao \& Wei, 2013; Han et al., 2015; Casper et al., 2019). For instance, the findings by Dolnicar (2010) show that many individuals display differing environmental behaviours at the tourism destination, as well as in their daily life at home, where they may be pro-environmental in their region of origin, but less so in the host destination, with the opposite also possibly being true. Moreover, Han et al. (2012) warn against viewing sport event attendees as a homogenous group, as pertaining to environmental behaviours and travel characteristics. Instead, the scholars posit that environmental behaviours tend to differ according to attendee type.

\section{Sport event attendees' behaviours at home and at the host destination}

The environmental behaviours of event attendees at home and at the host destination have come under investigation in recent years (Mair \& Laing, 2013; Han et al., 2015; Viviers et al., 2019). Pro-environmental behaviours at home refer to the pattern of activities that individuals perform to benefit the environment (Whitmarsh \& O'Neill, 2010; Muster \& Schrader, 2011; Viviers et al., 2019). Examples of such activities include minimising food and water waste, recycling, switching from the use of plastics to paper or other alternatives, efficient energy usage, and using greener transportation options and more environment-friendly products than before (Viviers et al., 2019). Such proenvironmental behaviours are ascribed to attitudinal and emotional aspects, with those concerned having a positive attitude towards the natural environment and therefore, acting in a manner that seeks to minimise the adverse human impact on the environment (Viviers et al., 2019). Some studies opine that adopting green attitudes, and engaging in pro-environmental behaviours, at home should influence the manner in which the attendees engage in pro-environmental messaging and behaviours at the tourism destination (Whitmarsh \& O’Neill, 2010; Muster \& Schrader, 2011). In contrast, other studies warn against the general assumption that environmentally aware individuals will practise pro-environmental behaviours at a destination, as such a relationship has not yet been conclusively proven (Lopez-Bonnilla et al., 2018).

A number of postulations have been projected as accounting for the inconsistencies between event attendees behaviours at home and at the destination. Increasingly, host event destination managers and event organisers have begun to incorporate proenvironmental messaging in the organising and hosting of sport events (Han et al., 2015; Lopez-Bonilla et al., 2018; Viviers et al., 2019). The above emerged from the realisation that those who are keen on destination environmental sustainability should not solely focus on incorporating environmental operations, like waste management systems and energy efficient facilities in their planning but rather, they should place additional focus on engaging with other stakeholders, such as the local community, to promote proenvironmental behaviours (Dolnicar \& Grun, 2009; Dolnicar, 2010). Han et al. (2015) opine the above as being the pro-sustainability information that should be shared with the sport event attendees. Additionally, emphasis has been placed on creating an 
environment that encourages pro-environmental behaviour, particularly in the stadia and sport facilities, as such action would serve to enforce the social norms governing behaviour. For instance, an individual would find it challenging to litter in an environment that is clean and evident of trash disposal (Miao \& Wei, 2013). Evidently, such studies suggest that individuals might behave more environmentally responsibly at a destination, owing to the influence of the pro-environmental message that is in place. Moreover, although in their study, Han et al. (2015) found environmental behaviour to decrease from that in their everyday life to that at the host event destination, the study argues that the inconsistency in environmental behaviour is, in part, determined by the environmental role played by the destination itself. Furthermore, in relation to the inconsistencies in environmental behaviours, between when those concerned are at home or at the host destination, the study by Lopez-Bonilla et al. (2018) is of interest. LopezBonnilla et al. (2018), having examined the pro-environmental behaviours acted out at a golf destination, concluded to two factors having influenced the sustainable behaviours of the attendees at the golf resort, being that they would engage in pro-environmental behaviour if they already possessed a positive environmental attitude, and if the environmental behaviour was easy and convenient to perform.

\section{The Transtheoretical Model}

Originally developed within the discipline of psychology, the transtheoretical model (TTM) of change has increasingly been used to explain changes in health behaviour, particularly when engaging in sport and exercise, as well as the understanding of pro-environmental behaviours (Tolkes \& Butzmann, 2018). While the use of TTM in tourism and hospitality is gaining prominence, only a few studies have used the model to analyse the environmental behaviour of sport event attendees (see Musgrave et al., 2019; Ramchandani et al., 2019). The core premise of the TTM states that individuals go through a series of five stages in adopting voluntary change in their daily life (Mair \& Laing, 2013; Tolkes \& Butzmann, 2018). The stages concerned are pre-contemplation, contemplation, preparation, action and maintenance (Musgrave et al., 2019).

Ramchandani et al. (2017) describe the stages as representing a spiral, with people starting at the bottom (in pre-contemplation), and moving through the different stages as they change their behaviour. In the pre-contemplation stage, individuals are unaware of any problem in their behaviours, and they, therefore, do not see themselves as possessing the need to alter, or change, their life in any way (Ramchandani et al., 2017; Musgrave et al., 2019). Only during the contemplation stage do the individuals become aware of the issues that require change, whereupon they start to analyse the pros and cons of changing their behaviours to the desired form, which, in the present context, constitute pro-environmental behaviours (Ramchandani et al., 2017). The model suggests that individuals become more open than before to persuasive messages that reinforce their intended behaviours, and that support their motivation, in becoming proenvironmentally conscious (Tolkes \& Butzmann, 2018). The first steps towards the performance of pro-environmental behaviour start in the preparation stage, while, in the action and maintenance stage, the individuals perform the desired behaviour, taking prosustainable action, but requiring help and support to continue to do so (Mair \& Laing, 2013; Tolkes \& Butzmann, 2018). The TTM additionally details the processes of changes, which identify how the change occurs (Musgrave et al., 2019; Ramchandani et al., 2019).

Mair and Laing (2013) point to the processes of change as being closely linked to the progression from one stage to the next. Of the ten processes of change, the first five, which are classified as experiential, are associated with the pre-contemplation, contemplation and preparation stages (Ramchandani et al., 2019). The experiential processes consist of consciousness-raising, dramatic relief, environmental re-evaluation, 
self-evaluation and social liberation (Ramchandani et al., 2019, p. 9). The last five processes of change are classified as behavioural, with them usually being associated with the action and maintenaGeography Bulletinnce stages (Ramchandani et al., 2019). The behavioural processes include self-liberation, reinforcement management, counterconditioning, stimulus control, and helping relationships (Musgrave et al., 2019).

The model is often used for its dynamic approach to behavioural change, in that the model clearly delineates that the individuals concerned may move forward and backwards throughout the stages and processes of change (Tolkes \& Butzmann, 2018). The model thereby accounts for the individuals who might achieve certain changes but who are at other stages in the model, and for those who regress to the precontemplation and contemplation stages (Tolkes \& Butzmann, 2018). Additionally, the model recognises that moments might occur where the individuals are stuck in one stage of change (Mair \& Laing, 2013). The strength of the model essentially lies its ability to consider the motivations, emotions and cognitions of the individuals (Mair \& Laing, 2013). While the TTM has only, so far, been scantily applied to tourism and sport events, the relevance of the model to the present study lies in its investigation of the attitudes of individuals, with it being postulated to be particularly useful in reaching an understanding of the engagement of sport event attendees, in terms of their proenvironmental behaviours at home, and at the destination (Tolkes \& Butzmann, 2018).

With some studies having found certain inconsistencies between the environmental behaviours at home and at the destination, the model aids in gaining an understanding of the pro-environmental behaviours of the attendees, in the context of female sport events. Additionally, the model can be applied to a wide array of behaviour change settings, as the constructs that it uses are of a global nature (Ramchandani et al., 2019). The present study therefore adopted the model to analyse the pro-environmental behaviour occurring at a major sport event hosted in Cameroon.

\section{MATERIALS AND METHODS}

The focus of the study was the twelfth edition of the Women Africa Cup of Nations, which was hosted in Cameroon in 2016. The event which is held every two years is managed by the Confederation of African Football (CAF). Since its inception in 1991 in response to the development and promotion of women's football on the African continent, the tournament has grown to become a major international sporting event, which can be likened to the men's tournament. The event has grown in stature, attracting major international sponsorship, and receiving increased media coverage, which augurs well for sport tourism in Africa. Regrettably, research into the cause and effects that are associated with the event on the continent has largely been neglected (see Achu, 2018).

Thus, the focus on the event, so as to examine the pro-environmental behaviour of the event attendees sheds more light on the sport tourism literature from an emerging destination context. The study was conducted in Yaounde and Limbe, which were the two host cities of the event. The researcher employed a mixed-methods research technique to collect the required data. Semi-structured questionnaire surveys were used to target the event attendees during the course of the event in both cities. The sample for the survey in both cities, was drawn using a sample calculator that was conceived for determining how large a randomly chosen sample from a given finite population of $n$ cases should be, such that the sample proportion $p$ would fall within .05 of the population proportion, meaning $p$ with a 95\% level of confidence (Isaac \& Michael, 1981). Consequently, the stadium capacity (42 500 for Stade Ahmadou Ahidjo in Yaoundé, and 20 ooo for the Limbe Omnisport Stadium in Limbe) determined the sample size to be $n=759$. To obtain valid responses from the attendees during the event, the researcher employed the assistance of 
fieldworkers. The fieldworkers were chosen for their ability to communicate effectively in both English and French, given that the survey which was developed in English was also transcribed into French (with the two languages both being the official languages of Cameroon). The fieldworkers were trained to target the non-local event attendees.

The surveys were conducted on a face-to-face basis with the respondents at the entry/exit points of the stadia, so as to ensure that every event attendee had an equal chance of taking part in the study. One in twenty attendees was approached to participate in the study. In terms of the attendees' profile, the study focused on the attendees' gender, age, and place of residency, as well as other sociodemographic factors. Their attributes were used to determine their demographic profiles. As indicated in Tables 1 and 2, two main variables were measured in the study, being the attendees' environmental behaviour at home, versus their behaviour during the event. In relation to ascertaining the respondents' environmental behaviour at home, ten variables were assigned, in relation to which they were asked to indicate their level of undertaking of a particular environmental friendly practice on a three-point scale, where $1=$ Never; $2=$ Sometimes; $3=$ Always.

In addition, the researcher also carried out "site observations focusing on the messages that the event was sending to attendees" (Mair \& Laing, 2013, p. 1118). The attendees were observed in terms of their activities and behaviour on key aspect of waste management. A total of 758 completed surveys were collected on the given match days for the duration of the tournament (between 9 November and 3 December 2016).

Despite the event being a female tournament, the respondents were found to be largely men (65\%) compared to women (35\%). They were fairly young, with the vast majority (83\%) being in the age range of between 18 and 44 years. Many of the respondents $(61 \%)$ had attained an undergraduate or postgraduate qualification. They were mainly either employed as businesspeople, or as professionals (71\%). In terms of geographical distribution, the majority of the respondents (67\%) were domestic tourists from other parts of Cameroon, while many (31\%) were from the other parts of the African continent. Interestingly, many of the respondents (78\%) travelled in groups, staying at the destination for an average of eight nights.

\section{RESULTS DISCUSSIONS}

\section{Environmental behaviour while at home}

The respondents were asked to indicate the environmentally friendly practices that they undertook while at home. Table 1 shows that, while the respondents seemed always to dispose of waste $(M=2.23)$, and to use public transport $(M=2.13)$, they indicated that they sometimes recycled $(M=1.85)$, reused water $(M=1.93)$, harvested water $(M=1.96)$, bought, or consumed less, water $(\mathrm{M}=1.95)$, purchased green, or fair trade, products $(\mathrm{M}=$ 1.93), composted home waste $(M=1.96)$, used alternative energy sources $(M=1.92)$, and planted trees $(M=1.99)$. The above could mean that, while they were at home, no strict monitoring of environmental behaviour was taking place, and, hence, they did not always behave in an environment-friendly manner. The result might also have meant that the respondents were aware of their environmental usage, despite their limited full-time environmental-friendly practice at home, which could have influenced their positive environmental behaviour in the host destinations, which required compliance with specific control measures. The assertion is made on the basis of a review of the proenvironmental behaviour literature, which argued that environmental behaviours and lifestyles in the home region largely influence environmental behaviour at destinations (see Mair \& Laing, 2013; Marks et al., 2016). Properly disposing of waste could be described as being the most common practice that the respondents described themselves as engaging in "always". The above was closely followed by the use of public 
transport, which contributes towards the reduction of the carbon footprint. While most of the respondents described themselves as being advocates for environmental protection, the survey determined, through the open-ended responses that most respondents gave, that they could be relatively cautious in their actions, with them blaming their errant behaviour on such factors as 'lack of time'. The respondents indicated that, due to their busy work schedule, they simply did not have enough time to recycle, or plant, trees. Consequently, most of the event attendees' home behaviour could be described as being characteristic of those in the contemplation stage (see Ramchandani et al., 2017) as the vast majority (92\%) mentioned that their behaviour, while they were at home, needed to be changed, and that they were willing to do so.

Table 1. Environment-friendly practices in which the respondents partook/participated while at home(Data source: based on fieldwork)

\begin{tabular}{|c|l|c|c|}
\hline Variable & Environment-friendly practice at home & M & SD \\
\hline V1 & Recycling & 1.85 & 0.636 \\
\hline V2 & Reusing of water & 1.93 & 0.623 \\
\hline V3 & Proper disposal of waste & 2.23 & 0.676 \\
\hline V4 & Water harvesting (storage of rainwater) & 1.96 & 0.665 \\
\hline V5 & Buying or consuming less & 1.95 & 0.621 \\
\hline V6 & Purchase of green / fair trade products & 1.93 & 0.666 \\
\hline V7 & Composting of home waste & 1.96 & 0.706 \\
\hline V8 & Use of alternative energy sources, like solar energy & 1.92 & 0.638 \\
\hline V9 & Planting of trees & 1.99 & 0.674 \\
\hline V10 & Use of public transport & 2.13 & 0.712 \\
\hline M = Mean, SD & Standard Deviation & & \\
\hline
\end{tabular}

\section{Environmental behaviour during the event}

As shown in Table 2, it was clearly apparent that the respondents' proenvironmental behaviour, while at the event, was different to their behaviour at home. The respondents' responses showed that they mostly: used water sparingly and efficiently, such as drinking tap water and taking showers, rather than bathing $(M=2.06)$; interacted with, and supported, the locals by purchasing local goods and services $(M=2.04)$; frequented establishments that used local services and products ( $M=2.01)$; used electricity efficiently, such as switching off the light and appliances when they were not in the room $(M=2.22)$; used public transport, like buses and trains $(M=2.14)$; and deposited their rubbish carefully (reducing, recycling and reusing) $(\mathrm{M}=2.19)$. The findings also showed that the respondents only sometimes conserved water by way of reusing towels $(M=1.75)$ at the accommodation establishment where they stayed for the duration of the event; purchased green/fair trade products $(\mathrm{M}=1.95)$; supported green projects that aimed to combat climate change $(\mathrm{M}=1.94)$; and donated to local charities and development programmes that focused on environmental conservation and preservation $(\mathrm{M}=1.96)$. Overall, the results indicated that, during the event, the respondents displayed behaviour that was consistent with those who were at the contemplation stage of the TTM (see Ramchandani et al., 2017; Mushgrave et al., 2019).

A few studies have alluded to the influence of destination environmental responsibility, that is, to clear pro-environmental messaging, aimed at encouraging sustainable behaviours (Mair \& Laing, 2013; Marks et al., 2016; Miao \& Wei, 2013; Han et al., 2015). The above results might suggest the contribution of the sport tourism industry towards promoting environmentally sustainable behaviours and the positive correlation seen in attendees' behaviour. The results show that the major sport attendees were aware of the environmental consequences of their behaviour, but that they chose which 
environmental aspects to observe and which to ignore while they were at home, based on their particular interests. In the case of attending major events, however, the attendees' environmental behaviour around the event areas was guided by the environmental regulations and requirements concerned, as stipulated by the sport organisers and the environmental managers. Han et al. (2015), especially, called for a focus to be laid on individuals' behaviour at home and at the destination, having found that individuals are likely to display less pro-environmental behaviours at the destination, as compared to what they display in their home region. As the above findings highlighted the limited sustainable behaviours displayed at home, the pro-environmental behaviours evident in the destination could have been largely influenced by the destination setting and by the various pro-environmental strategies put in place by the sport event organisers.

Table 2. Environment-friendly practices undertaken

by the respondents during the event (Data source: based on fieldwork)

\begin{tabular}{|c|l|c|c|}
\hline Variable & \multicolumn{1}{|c|}{ Environment-friendly practice during travel } & M & SD \\
\hline V1 & Conserving of water, such as the reusing of towels & 1.75 & 0.633 \\
\hline V2 & $\begin{array}{l}\text { Sparing and efficient use of water, such as drinking tap water and } \\
\text { taking showers rather than bathing }\end{array}$ & 2.06 & 0.59 \\
\hline V3 & $\begin{array}{l}\text { Interacting with, and supporting of, locals by means of } \\
\text { purchasing local goods and services }\end{array}$ & 2.04 & 0.639 \\
\hline V4 & Frequenting of establishments that use local services and products & 2.01 & 0.618 \\
\hline V5 & $\begin{array}{l}\text { Efficient usage of electricity, such as switching off the light and } \\
\text { appliances when not in the room }\end{array}$ & 2.22 & 0.659 \\
\hline V6 & Purchase of green/fair trade products & 1.95 & 0.662 \\
\hline V7 & Supporting of green projects & 1.94 & 0.682 \\
\hline V8 & Donating to local charities and development programmes & 1.96 & 0.679 \\
\hline V9 & Use of public transport, like buses and trains & 2.14 & 0.672 \\
\hline V10 & Careful depositing of rubbish (reducing, recycling and reusing) & 2.19 & 0.686 \\
\hline
\end{tabular}

The above findings point to the environmental behaviour of the major sport event attendees being generally positive both at home and when they attend events. However, there is evidence of consistencies in their environmental behaviour and in their commitment to environmental sustainability. The above confirms the patterns observed in terms of behavioural change in the TTM, which observed that individuals might move forward and backwards throughout the stages and processes of change (Tolkes \& Butzmann, 2018). Despite the positive response indicated above, the current researchers wish to encourage the major sport organisers and environmental managers to continue to relook at how environmental strategies and policies are incorporated into sport tourism development, especially regarding the promotion of pro-environmental behaviour.

The current study findings suggest that assessing the environmental behaviour of major sport event attendees should be recognised, with the efforts involved being directed at streamlining environmental sustainability commitments and mechanisms in terms of the vision, mission and strategies of the major sports organisations, and according to the statutes of the public sector and environmental bodies concerned.

With the environmental footprint of sport becoming increasingly significant (Suzuki, 2007; McCullough et al., 2016), the concerned stakeholders in the major sport event planning undertaken by the host destinations should play a role in necessitating a response to environmental issues emanating from the sport fans' behaviour during such events. The above should include such measures as continuing to encourage visitors to utilise public transport when traveling to the stadia and to purchase green/fair trade products during their stay, among other environment-friendly actions. More strategic 
environmental impact assessment techniques must be employed than at present, in managing the environmental practices of the event attendees, so that the major sports organisations and policymakers can be supplied with useful information and guidelines regarding environmental management and the monitoring of behaviour.

In a related study by Collins et al. (2009), the Ecological Footprint Analysis and the Environmental Input-Output analysis were proposed as being two of the best approaches that sport organisations can employ to manage the environmental behaviour of stakeholders when attending major sporting events. On one hand, the Ecological Footprint Analysis measures the global impact of environmental behaviour, while, on the other hand, the Environmental Input-Output analysis measures the local impacts made in the above regard. The two techniques are crucial to the implementing of a major football event, because doing an Environmental Input-Output analysis (1) allows for assessing the overall economic and environmental consequences of sporting events for the host region, and (2) evaluates the global impacts of stakeholders' environmental behaviour and resource consumption during a sporting event that has global consequences, in terms of pollution and, ultimately, climate change.

\section{CONCLUSION}

Encouraging the pro-environmental behaviour of major sport event attendees is an important component of event sustainability (Mair \& Liaing, 2013). The current study focused on assessing the environmental behaviour displayed by event attendees at home and at a major event. The study found inconsistencies in terms of the behaviour displayed at home versus while they were at the event, which triggered academic interest as to how such behaviour could be managed to bring about consistency in the behaviour, irrespective of whether the individuals concerned are at home, or at an event. Typically, since the event attendees were likely to be more pro-environmentally friendly during the event than at home, as the study findings show, such events can be seen as critical avenues to creating a lasting impression on the attendees that could address their behaviour during the event and encourage it to continue thereafter at home. In the above sense, the learning experience provided through initiatives and branded messages during an event can be seen as being very important.

The above could be achieved through adopting a concerted event stakeholder approach, in terms of which all the concerned and affected stakeholders, including sport organisations, the public sector, the environmental departments, the private sector, the non-profit organisations (NPOs) and the host community members, are lured into entering into a symbiotic relationship, where all the decisions made regarding the event in question represent their views and opinions. The above could help with the premonitoring and managing of environmental issues associated with the event.

\section{Acknowledgements}

The study forms part of a PhD in Human and Social Sciences at the University of KwaZulu-Natal in South Africa. The author acknowledges inputs to the paper from Prof Urmilla Bob, Logistic Makoni and Refiloe Lekgau. The author acknowledges the assistance of the fieldworkers who assisted with the data collection.

\section{REFERENCES}

Achu, F.N. (2018). Profiling attendees at a major women's football event in Cameroon, EuroEconomica, 37(8), $231-244$. Adams, A. \& Piekarz, M. (2015). Sport events and human rights: Positive promotion or negative erosion?, Journal of Policy Research in Tourism, Leisure \& Events, 7, 220-236. 
Alonso-Vazquez, M., Packer, J., Fairley, S. \& Hughes, K. (2019). The role of place attachment and festival attachment in influencing attendees' environmentally responsible behaviours at music festivals, Tourism Recreation Research, 44(1), 91-102.

Babiak, K. \& Trendaflova, S. (2011). CSR and environmental responsibility: Motives and pressures to adopt green management practices, Corporate Social Responsibility and Environmental Management, 18(1), 11-24.

Balduck, A., Maes, M. \& Buelens, M. (2011). The social impact of the Tour de France: Comparisons of residents' pre- and post-event perceptions, European Sport Management Quarterly, 11(2), 91-113.

Bama, H.K.N. \& Tichaawa, T.M. (2015). Major sporting events and responsible tourism: Analysis of the 2013 Africa Cup of Nations (AFCON) tournament in Port Elizabeth, South Africa, African Journal for Physical, Health Education, Recreation and Dance (AJPHERD), Supplement 1 (December), 205-219.

Bell, B. \& Daniels, J. (2018). Sport development in challenging times: Leverage of sport events for legacy in disadvantaged communities, Managing Sport and Leisure, 23(4-6), 369-390.

Boggia, A., Massi, G., Paolotti, L., Rocchi, L. \& Schiavi, F. (2018). A model for measuring the environmental sustainability of events, Journal of Environmental Management, 26, 836-845.

Bohlmann, H.R. \& Van Heerden, M.J.H. (2005). The impact of hosting a major sport event on the South African economy, Working Papers 200509, University of Pretoria, Department of Economics, Pretoria.

Cantelon, H. \& Letters, M. (2000). The making of the IOC environmental policy at the third dimension of the Olympic Movement, International Review for the Sociology of Sport, 35(3), 294-308.

Casper, J.M., McCullough, B.P. \& Pfahl, M.E. (2019). Examining environmental fan engagement initiatives through values and norms with intercollegiate sport fans, Sport Management Review, https://doi.org/10.1016/j.smr.2019.03.005

Chirieleison, C., Montrone, A. \& Scrucca, L. (2019). Event sustainability and sustainable transportation: A positive reciprocal influence, Journal of Sustainable Tourism, DOI: 10.1080/09669582.2019.1607361

Collins, A. \& Flynn, A. (2008). Measuring environmental sustainability of a major sporting event: A case of the FA Cup Final, Tourism Economics, 14(4), 751-768.

Collins, A., Jones, C. \& Munday, M. (2009). Assessing the environmental impacts of mega sports events: Two options? Tourism Management, 20, 828-837.

Davies, L.E. (2010). Sport and economic regeneration: A winning combination? Sport in Society, 13(10), 1438-1457.

Davies, L.E. (2016). A wider role for sport: Community sports hubs and urban regeneration, Sport in Society, 19(10), 1537-1555.

Djaballah, M. Hautbois, C. \& Desbordes, M. (2015). Non-mega sporting events' social impacts: A sensemaking approach of local governments' perceptions and strategies, European Sport Management Quarterly, 15(1), 48-76.

Dolf, M. \& Teehan, P. (2015). Reducing the carbon footprint of spectator and team travel at the University of British Columbia's varsity sports events, Sport Management Review, 18, 244-255.

Dolnicar, S., \& Grun, B. (2009). Environmentally friendly behavior can heterogeneity among individuals and contexts/environments be harvested for improved sustainable management? Environment and Behavior, 41, 693-714.

Dolnicar, S. (2010). Identifying tourists with smaller environmental footprints, Journal of Sustainable Tourism, $18,717-734$.

Fekry, A.A., Zafarany, A.M.E. \& Shamseldin, A.K.M., (2014), Develop a flexible method to assess building hosting major sport events environmentally through the world, Hosing and Building National Research Center, 10, 127-137.

Foss, J. (2009). Beyond environmentalism: A philosophy of nature, Wiley, Hoboken, NJ.

Fyall, D. \& Jago, L. (2009). Sustainability in sport \& tourism, Journal of Sport and Tourism, 14(2-3), 77-81.

Habitzreuter, A.M. \& Koenigstorfer, J. (2018). The impact of environmental CSR-linked sport sponsorship on attitude toward the sponsor depending on regulatory fit, Journal of Business Research (In press), https://doi.org/10.1016/j.jbusres.2018.11.040

Han, J.H., Nelson, C.M. \& Kim, C. (2015). Pro-environmental behavior in sport event tourism: Roles of event attendees and destinations, Tourism Geographies, 17(5), 719-737.

Hart, S. \& Milstein, M. (2003). Creating sustainable value, Academy of Management Executive, 17(2). 56-67.

Hart, S. (1995). A natural resource based view of the firm, Academy of Management Review, 20(4), 986-1014.

Hemmonsbey, J., Tichaawa, T. \& Knott, B. (2018). Conceptual framework for strategic destination branding through leveraging home-grown sport events, South African Journal for Research in Sport, Physical Education and Recreation, 40(2), 81-98.

Hemmonsbey, J. \& Tichaawa, T. (2018a). The effects of major sport event leveraging for tourism and destination branding: The case of South Africa as an emerging destination, GeoJournal of Tourism and Geosites, $1(21), 213-225$. 
Hemmonsbey, J. \& Tichaawa, T. (2018b). Using non-mega events for destination branding: A stakeholder perspective, GeoJournal of Tourism and Geosites, 24(1), 81-98.

Hemmonsbey, J. \& Tichaawa, T.M. (2019). Using non-mega events for destination branding: A stakeholder perspective, GeoJournal of Tourism and Geosites, 24(1), 252-266.

Inoue, Y. \& Kent, A. (2012). Sport teams as promoters of pro-environmental behavior: An empirical study, Journal of Sport Management, 26(5), 417-432.

Isaac, S. \& Michael, W.B. (1981). Handbook in research and evaluation, EdITS, San Diego, CA.

Jones, C. (2008). Assessing the environmental impact of a major sporting event, Tourism Economics, 14, 343-360.

Kellison, T.B. \& Kim, Y.K. (2014). Marketing pro-environmental venues in professional sport: Planting seeds of change among existing and prospective consumers, Journal of Sport Management, 28, 34-48.

Kollmuss, A. \& Agyeman, J. (2002). Mind the gap: Why do people act environmentally and what are the barriers to pro-environmental behavior? Environmental Education Research, 8(3), 239-260.

Li, S. \& Jago, L. (2013). Evaluating economic impacts of major sport events: A meta-analysis of the key trends, Current Issues in Tourism, 16(6), 591-611.

López-Bonilla, J.M., Reyes-Rodríguez, M.C. \& López-Bonilla, L.M. (2018). The environmental attitudes and behaviours of European golf tourists, Sustainability, 10(2214), 1-16.

MacIntyre, E., Walkin, M., Beckmann, J., Calogiuri, G., Gritzka, S., Oliver, G., Donnelly, A. \& Warrington, G. (2019). An exploratory study of extreme sport athletes' nature interactions: From well-being to proenvironmental behaviour, Frontiers in Psychology, 10(1233), 1-13.

Mair, J. \& Laing, J.M. (2013). Encouraging pro-environmental behaviour: The role of sustainability-focused events, Journal of Sustainable Tourism, 21(8), 1113-1128.

Mallen, C., Stevens, J., Adams, L. \& McRoberts, S. (2010). The assessment of the environmental performance of an international multi-sport event, European Sport Management Quarterly, 10(1), 97-122.

Marks, M., Chandler, L. \& Baldwin, C. (2016). Re-imagining the environment: Using an environmental art festival to encourage pro-environmental behaviour and a sense of place, Local Environment, 21(3), 310-329.

McCullough, B.P. \& Cunningham, G.B. (2010). A conceptual model to understand the impetus to engage in and the expected organizational outcomes of green initiatives, Quest, 62(4), 348-363.

McCullough, B.P., Pfahl, E. \& Nguyen, S.N. (2016). The green waves of environmental sustainability in sport, Sport in Society, 19(7), 1040-1065.

McCullough, B.P. \& Kellison, T.B. (2016). Go green for the home team: Sense of place and environmental sustainability in sport, Journal of Sustainability Education, 11, 1-14.

McCullough, B.P., Pfahl, M.E. \& Nguyen, S. (2015). The green waves of environmental sustainability in sport, Sport in Society: Cultures, Commerce, Media, Politics, 19(7), 1040-1065.

Miao, L. \& Wei, W. (2013). Consumers' pro-environmental behavior and the underlying motivations: A comparison between household and hotel settings, International Journal of Hospitality Management, 32, 102-112.

Minoli, D.M., Goode, M.M.H. \& Metcalfe, A.W. (2018). Are sport tourists of an environmental mindset to drive the green? The case of golfers, Tourism Management Perspectives, 25, 71-79.

Musgrave, J., Jamson, S. \& Jopson, A. (2019). Travelling to a sport event: Profiling sport fans against the Transtheoretical Model of Change, Journal of Hospitality and Tourism Research (In Press).

Muster, V. \& Schrader, U. (2011). Green work-life balance: A new perspective for green HRM, German Journal of Human Resource Management, 25(2), 140-156.

Oliver, C. (1992). The antecedents of deinstitutionalization, Organizational Studies, 13, 563-588.

Pereira, G., Ganser, R., Wood, G. \& De Conto, S.M. (2014). Environmental impact assessment and the planning process of major sports events in Brazil: A case study of the Rio 2007 Pan American Games, Impact Assessment and Project Appraisal, 32(1), 55-65.

Pfahl, M. (2011). Sport and the natural environment: A strategic guide, Kendall Hunt, Dubuque.

Pfahl, M. (2013). The environmental awakening in sport, Solutions Journal, 4(3), 67-76.

Prizzia, R. (2007). Sustainable development in an international perspective, In Handbook of globalization and the environment, Thai, K., Rahm, D. \& Coggburn, J.D., 19-42, CRC Press, New York.

Ramchandani, G., Kokolakakis, T. \& Coleman, R. (2014). Factors influencing the inspirational effect of major sports events on audience sport participation behaviour, World Leisure Journal, 56(3), 220-235.

Ramchandani, G., Coleman, R. \& Bingham, J. (2017). Sport participation behaviours of spectators attending major sports events and event induced attitudinal changes towards sport, International Journal of Event and Festival Management, 8(2), 121-135.

Ramchandani, G., Coleman, R. \& Christy, E. (2019). The sport participation legacy of major events in the UK, Health Promotion International, 34(1), 1-15.

Russo, M. \& Fouts, P. (2007). A resource-based perspective on corporate environmental performance and profitability, Academy of Management Journal, 40(3). 534-559. 
Schimmel, K.S. (2012). Major sport events and global threats/responses, Criminal Justice Matters, 88(1), 20-21.

Schnitzer, M., Schlemmer, P. \& Kristiansen, E. (2017). Youth multi-sport events in Austria: Tourism strategy or just a coincidence? Journal of Sport \& Tourism, 21(3), 179-199.

Sebake, T.N. \& Gibberd, J.T. (2008). Assessing the sustainability performance of the 2010 FIFA World Cup stadia using the sustainable building assessment tool (SBAT) for stadia, in 5th Post Graduate Conference on Construction Industry Development, Bloemfontein, South Africa, 16-18 March 2008, http:// researchspace.csir.co.za/dspace/handle/10204/3238

Sotiriadou, P. \& Hill, B.A. (2015). Raising environmental responsibility and sustainability for sport events: A systematic review, International Journal of Event Management Research, 10(1), 1-12.

Smith, A. (2009). Theorising the relationship between major sport events and social sustainability, Journal of Sport \& Tourism, 14, 2-3, 109-120.

Suzuki, D. (2007). The sacred balance: Rediscovering our place in nature, Greystone Books, Vancouver.

Taks, M. (2013). Social sustainability of non-mega sport events in a global world, European Journal for Sport and Society, 10(2), 121-141.

Taks, M., Chalip, L., \& Green, C.B., (2015), Impacts and strategic outcomes from non-mega sport events for local communities, European Sport Management Quarterly, 15(1), 1-6.

Thibault, L. (2009). Globalization of sport: An inconvenient truth, Journal of Sport Management, 23, 1-20.

Tichaawa, T.M. \& Swart, K. (2010). Cameroonian fans' perceptions of the 2010 FIFA World Cup: A case study of Buea and Limbe, Alternation, 17(2), 173-199.

Tichaawa, T.M. \& Bob, U. (2015). Leveraging mega-events beyond the host nation: A case study of the 2010 FIFA World Cup African Legacy Programme in Cameroon and Nigeria, Leisure Studies, 34(6), 742-757.

Tichaawa, T.M. \& Harilal, V. (2016). Golf tourism in South Africa: Profiling attendees at a major championship event, African Journal for Physical Activity and Health Sciences (AJPHES), 22(1), 795-807.

Tichaawa, T., Bob, U. \& Swart, K. (2018). Africa and sports tourism, in Sport in the African world, 185-204. Nauright, J. \& Amara, M., Routledge, London.Trendafilova, S., Babiak, K. \& Heinze, K. (2013). Corporate social responsibility and environmental sustainability: Why professional sport is greening the playing field, Sport Management Review, 16(3), 298-313.

Tolkes, C. \& Butzmann, E. (2018). Motivating pro-sustainable behavior: The potential of green events-A casestudy from the Munich Streetlife Festival, Sustainability, 10(3731), 1-15.

Turco, D.M., Tichaawa, T.M., Moodley, V., Munien, S., Jaggerneth, J. \& Stofberg, Q.S. (2012). Profiles of foreign visitors attending the 2010 FIFA World Cup in South Africa. African Journal for Physical, Health Education, Recreation and Dance, September (Supplement 1), 73-80.

Viviers, P., Botha, K. \& Marumo, E. (2019). "Actions speak louder than words": Comparing attendees' green behaviour at home with their inclination to support green practices at arts festivals, African Journal of Hospitality, Tourism and Leisure, 8(4), 1-18.

Wernerfelt, B. (1984). A resource-based view of the firm, Strategic Management Journal, 9(3), 427-443.

Whitmarsh, L. \& O'Neill, S. (2010). Green identity, green living? The role of pro-environmental self-identity in determining consistency across diverse pro-environmental behaviours, Journal of Environmental Psychology, 30(3), 305-314.

Xue, H. \& Mason, D.S. (2017). Sport events, urban regimes, and community development: A case study of Nanjing, China, Managing Sport and Leisure, 22(4), 325-341.

*** Fédération Internationale de Football Association, (FIFA) (2013). Football for the Planet, FIFA, Zurich.

*** United Nations Environmental Programme, (2009), Beijing 2008 Olympic Games, United Nations Environmental Programme, Division of Communications and Public Information, Nairobi.

Submitted:

08.07.2019
Revised:

13.12.2019
Accepted and published online 16.12.2019 